\title{
DESIGN OF A KNEE EXOSKELETON ASSISTING DURING WALKING, SIT-TO- STAND, AND STAIR ASCENDING
}

\author{
Furkan M. BíLGi'1, Ramazan UNAL ${ }^{2 *}$
}

${ }^{1}$ Abdullah Gul University, Engineering Faculty, Department of Mechanical Engineering, Kayseri, Türkiye ${ }^{2}$ Ozyegin University, Engineering Faculty, Department of Mechanical Engineering, İstanbul, Türkiye

\begin{tabular}{ll}
\hline Keywords & Abstract \\
\hline Exoskeleton Design, & In this study, we present a knee exoskeleton that assists weight acceptance in \\
Assistive Devices, & walking, sit-to-stand and stair ascending. Working principle of the exoskeleton \\
Walking, & device is inspired from the bio-mechanical data of natural human gait, sit to stance \\
Sit-to-Stand, & and stair ascent motions. First, we analyze the natural gait data to identify the \\
Stair Ascend. & weight acceptance behavior of the knee joint. Then we build a model for sit to \\
stand motion with an elastic element. After that, stair ascent data is analyzed in a \\
similar manner. Then, we define the appropriate elastic elements, their coefficients \\
and motor requirements if necessary, for these specific tasks. Finally, we present \\
the CAD model of the proposed knee exoskeleton.
\end{tabular}

\section{YÜRÜME, OTURMA-KALKMA VE MERDIVEN ÇIKMA SIRASINDA YARDIMCI OLAN DİZ DIŞ} ISKELETININ TASARIMI

\author{
Anahtar Kelimeler \\ Dıs İskelet Tasarımı, \\ Yardımcı Cihazlar, \\ Yürüme, \\ Oturma-Kalkma, \\ Merdiven Çıkma.
}

\begin{abstract}
Öz
Bu çalışmada, yürümede, ayağa kalkmada ve merdiven çıkmada ağırlık kabulüne yardımcı olan bir diz dış iskeletini sunuyoruz. Dış iskelet cihazının çalışma prensibi, doğal insan yürüyüşü, ayağa kalkma ve merdiven çıkma hareketlerinin biyo-mekanik verilerinden esinlenmiștir. İlk olarak, diz ekleminin ağırlık kabul davranışını belirlemek için doğal yürüyüş verileri analiz edilmiştir. Ardından, elastik bir elemanla ayağa kalkma hareketi için bir model oluşturulmuştur. Bundan sonra, merdiven çıkma verileri benzer şekilde analiz edilmiştir. Ardından, bu hareketler için uygun elastik elemanları, bunların elastik katsayıları ve gerekirse motor gereksinimleri tanımlanmıştır. Son olarak, önerilen diz dış iskeletinin CAD modeli sunulmuştur.
\end{abstract}

\section{Alıntı / Cite}

Bilgi, F.M., Unal, R., (2021). Design Of A Knee Exoskeleton Assisting During Walking, Sit-to-Stand, and Stair Ascending, Journal of Engineering Sciences and Design, 9(3), 1003-1014.

\begin{tabular}{l|l|l}
\hline Yazar Kimliği / Author ID (ORCID Number) & Makale Süreci / Article Process \\
\hline F. M. Bilgi, 0000-0002-5235-6688 & Başvuru Tarihi / Submission Date & 31.08 .2020 \\
R. Unal, 0000-0002-2129-797X & Revizyon Tarihi / Revision Date & 14.08 .2021 \\
& Kabul Tarihi / Accepted Date & 31.08 .2021 \\
& Yayım Tarihi / Published Date & 21.09 .2021 \\
\hline
\end{tabular}

\section{Introduction}

The lower-limb assistive devices (exoskeletons or prostheses) are vital tools to assist or augment the capabilities of individuals in need for their daily activities in life. For instance, these devices aid amputees, people with muscle weaknesses and gait disorders (Indego, 2017; ReWalk, 2017). Additionally, lower limb assistive devices can reduce the metabolic cost of walking (van Dijk and van der Kooij, 2014; Shamaei et.al., 2014; Bacek et.al., 2015) or running (Dollar and Herr, 2008) and also enhance the capacity to lift and carry heavy loads of people such as infantry soldiers, firefighters, disaster relief workers etc. (Kazerooni et.al., 2006; Lockheed, 2017; Againer-ski, 2017; Liu and Low, 2004). Another utilization of these devices is rehabilitation. These devices are used in order to assist/drive the leg of patients (stroke patient, patients with muscle weaknesses etc.) to track the desired trajectory so that they can regain their motor control abilities (Banala et.al., 2007; van der Kooij et.al., 2006; Wu et.al., 2016; Rex, 2017; Jezernik et.al., 2003) as in upper limb rehabilitation (Kiguchi et.al., 2003; Hu

\footnotetext{
* ilgili yazar/Corresponding author: ramazan.unal@ozyegin.edu.tr, +90-216-564-9346
} 
et.al., 2009; Cheng et.al., 2003; Sasaki et.al., 2005). Additionally, modeling studies have also been carried out for these devices to evaluate interaction torque values (Baser et.al., 2018) and to obtain damping co-efficients and passive torque values that needs to be generated by the actuators to avoid instabilities on robotic joints (Demiray et.al., 2014). Furthermore, variable stiffness actuator designs for lower limb exoskeleton joints are compared in terms of energy consumption and power requirements (Kizilhan et.al., 2014).

Assistive devices would be classified into three main categories according to their actuation principle: active, passive and semi-active devices. Active assistive devices require external energy source to augment individuals' capability by means of actuators and controllers. For example, BLEEX is an active device that consists 7 degrees of freedom (DoF) and four of them are actuated by linear hydraulic actuators. It consumes $1140 \mathrm{~W}$ of electric power (Kazerooni et.al., 2006). Xiaopeng et. al. designed an exoskeleton (Liu and Low, 2004) that has 6 motors on joints (hip, knee and ankle) and two linear actuators to control the torso. ALEX is another active assistive device consisting 7 DoF, 2 of which are actuated by linear actuators (Banala et.al., 2007)). Exoskeleton in (van der Kooij et.al., 2006) is also an active exoskeleton which is used for rehabilitation purpose. This exoskeleton employs series elastic actuator that is driven by Bowden cables to actuate the joints. BioComEx also employs variable stiffness actuaotors on ankle joints and series elastic actuators on the knee and hip joints (Baser et.al., 2019) and in its latest version it employs hybrid actuators with MR brakes for achieving variable impedance lower limb exoskeleton in a safe and stable manner (Baser et.al., 2020) which was previously. Exoskeleton designed by Wu et.al. (2016) has three dc motors to drive the joints. The exoskeleton in (Jezernik et.al., 2003) has 4 DoF which are actuated with linear actuators. There are also some commercially available active exoskeletons, e.g. Indego (2017), REX (2017), ReWalk (2017) etc. Passive devices on the other hand, assist users by exploiting the kinematics and/or dynamics with their design specifically done for that task. These devices may employ elastic elements, dampers but no external power source. For instance, exoskeleton that is built in (van Dijk and van der Kooij, 2014) has artificial tendons to provide torques about joints. Similarly, exoskeleton in (Agrawal et.al, 2006) is a passive exoskeleton that has springs for building up torque. FORTIS (Lockheed, 2017) and Againer-ski (2017) can be given as example for commercial passive exoskeletons. Lastly, in semi-active devices, actuation is not used to actuate the joints directly but used to engage or disengage the equipment that provide torque about joints such as springs, dampers, tendons etc. For example, in (Shamaei et.al., 2014), researchers used controlled electromechanical clutch to engage and disengage the spring in order to build up torque about the joint at correct phase of gait. In (Dollar and Herr, 2008), exoskeleton consists a motorized mechanism to activate and deactivate the spring.

Among these devices, there are some knee exoskeletons that assist certain tasks. For example, the exoskeleton in (Shamaei et.al., 2014) is a knee exoskeleton that has a clutch mechanism to engage-disengage the spring so that the exoskeleton assists the weight acceptance phase of gait. The exoskeleton in (Beyl et.al., 2007) is an active knee exoskeleton which employed pleated pneumatic muscles and this device is designed for gait rehabilitation. The RoboKnee (Pratt et.al., 2004) is also a knee exoskeleton assisting individuals to carry heavy loads and stair climbing. In (Cai et.al., 2011), the exoskeleton has 6 DoF and one of them is actuated. This device aids the individuals for flexion and extension of knee. The exoskeleton in (Kim et.al., 2015) helps hemiplegic patients to walk normally. A self-aligning knee exoskeleton has been presented in (Celebi et.al., 2013) and a reconfigurable ankle exoskeleton for rehabilitation has been presented in (Erdogan et.al., 2016). Additionally, an adaptive knee joint for body weight support in lower limb exoskeleton (Wang et.al., 2016) has been presented. They also showed several advantages with their design over some other weight supporting lower limb exoskeletons. Since weight acceptance is the dominant function of the knee joint during stance phase of gait, this function is crucial for the design of a knee exoskeleton for supporting walking. Moreover, during this phase of the gait human knee joint undergoes about $15^{\circ}$ of flexion followed by an extension and it has been observed that when a healthy individual walks without this flexion, they expend $25 \%$ more extra metabolic energy than normal (Zissimopoulos et.al., 2007). The same situation is valid for the sit-stand movement; up to 70\% of the mechanical work during this task is provided by the knee joint (Wretenberg and Arborelius, 1994) and due to the lack of extension moment in the knee joint, individual performs this movement with the power he/she gets from his/her healthy leg in case of an amputation (Highsmith et.al., 2011) from his/her arms or increased postural sway and weight-bearing asymmetry occur between the affected and unaffected legs (Cheng et.al., 2001; Lee et.al., 1997). With this aim, the AlterG Bionic Leg (Wong et.al., 2012) knee exoskeleton is developed for assisting sit-to-stand, but it has limitations on torque controllability, speed capability, and mass. A design of a variablestiffness knee exoskeleton for mimicking able-bodied sit-to-stand is proposed in (Karavas et.al., 2015) and a flexion-assistance knee exoskeleton with low output impedance, SERKA, is developed and tested on stroke subjects in (Sulzer et.al., 2009). Also, in (Shepherd and Rouse, 2017) torque controllable knee exoskeleton is developed for assisting sit-to-stand motion. The design is based on series elastic actuation and employs a series fiberglass spring which improves closed-loop torque controllability with the addition of small mass. On the other hand, stair climbing requires a large amount of positive work at the knee joint (Wilken et.al., 2011). Based on this, it is emphasized that the actuator design can reduce the power requirements and series elastic actuators 
which is a combination of a DC motor and an elastic element connected in series are widely employed in exoskeletons due to their low impedance output capability (Paine, et.al., 2014).

In this study we propose a knee exoskeleton design that is able to assist weight acceptance, sit to stand and stair ascent. First the biomechanical data of these motions were analyzed. Then according to kinematics and kinetics of our design, we determined the number of springs and their coefficients. Moreover, the actuator that is used for assisting in stair ascent motion was determined.

\section{Methods}

\subsection{Walking Data of Knee Joint}

The biomechanics of human lower limb joints has been studied in detail and all the critical definitions about the human gait has been given in (Winter, 1991). In the first flexion of knee as shown in Figure 1, between $0-14 \%$ of the gait cycle, knee accepts the body weight (weight acceptance-WA) which corresponds to K1 area in power plot of knee joint. K1 is the largest energy storage area during gait. Then knee extends between 14-40\% of the gait cycle, to lift the body (Area K2). This extension following the first flexion can be identified as releasing the energy that is stored in the first flexion part around the knee joint. After this, the second flexion occurs (K3) which plays a vital role during gait. It is mainly the preparation of the next step and provides sufficient clearance to prevent the foot to strike the ground prematurely. Around 60\% of the gait cycle, toe-off (T0) occurs so the foot leaves the ground completely. Around $72 \%$ of the stride the second extension of knee joint takes place (K4). These second flexion and extension correspond to swing phase of gait.
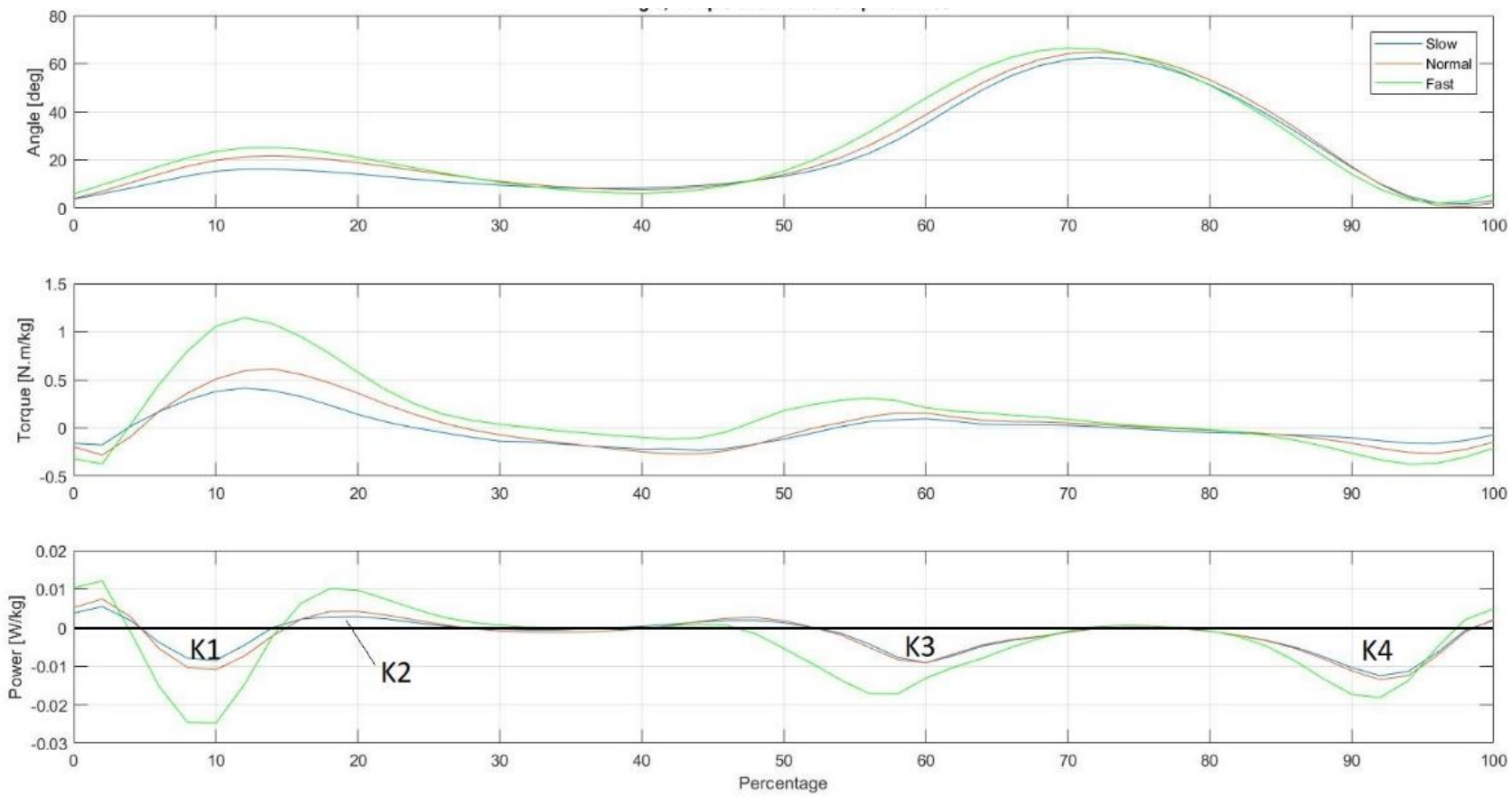

Figure 1. Angle, torque and power plot of natural knee Joint (Winter, 1991)

\subsection{Sit-to-Stand Data of Knee Joint}

Sit to stand motion can be described as to raise the body around knee joint. As it has been approximated according to the related knowledge (Plagenhoef, et.al., 1983), human upper body mass is considered to be approximately the two third of the total body mass, therefore we assigned $50 \mathrm{~kg}$ for upper body mass and $0.45 \mathrm{~m}$ for thigh length which corresponds to $1.8 \mathrm{~m}$ and $75 \mathrm{~kg}$ individual. The exoskeleton accompanied by the upper body mass to mimic this motion is shown in Figure 2. In this study, we modeled sit to stand motion statically since this motion is considered to be rather slow and effect of dynamics can be neglected. 


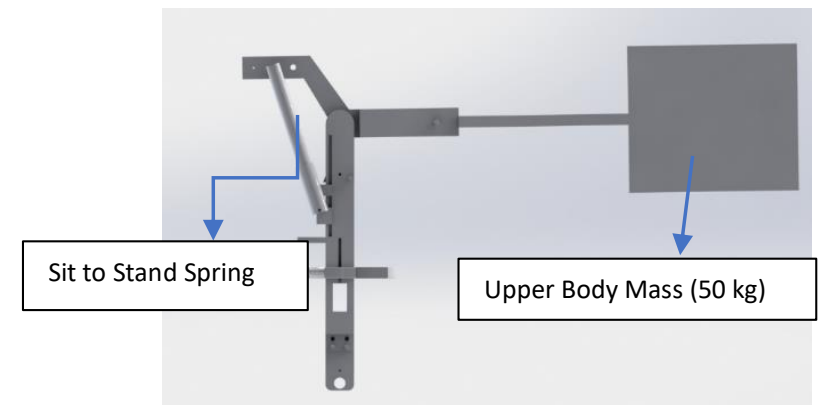

Figure 2. Knee exoskeleton and mass representing the rest of the human

The plot in Figure 3 depicts the torque behavior of knee joint during stand to sit motion. Torque value starts from $0 \mathrm{~N}-\mathrm{m}$ and it gets higher as the angle of knee joint increases. Even though this relation shows some nonlinearity towards the end, in order to avoid the design complexily, we approximate this relation by using a single linear spring instead of several linear springs in parallel which engage and disengage at different deflections to approximate the non-linear knee joint torque curve.

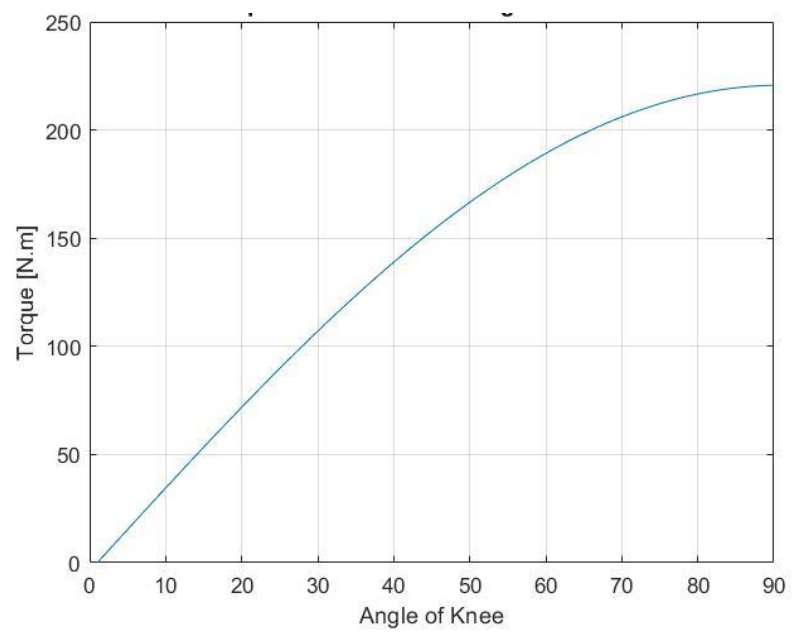

Figure 3. Torque of knee joint during stand to sit

\subsection{Stair Ascending Data of Knee Joint}

Angle, moment and power plots of knee during stair ascent motion are depicted in Figure 4. Angle of knee starts from nearly $70^{\circ}$ to $10^{\circ}$ and it increases until it reaches approximately $95^{\circ}$ and decreases to nearly $70^{\circ}$ for ascending stairs. Toe off starts at $60 \%$ of one cycle. Besides, knee moment starts from 0 [N.m/kg] and it increases to approximately $1.15[\mathrm{~N}-\mathrm{m} / \mathrm{kg}]$ because the knee joint is responsible for raising the body on the stair. Then it decreases drastically to about $0[\mathrm{~N}-\mathrm{m} / \mathrm{kg}]$. Yet, we can see some fluctuation that is caused by the swing motion of the leg. Knee joint must provide the most of the moment until $\sim 18 \%$ and this moment is decreased linearly until $\sim 52 \%$. Raising the body by knee corresponds to power generation boost in power plot. Power generation increases from $0[\mathrm{~W} / \mathrm{kg}]$ to $\sim 2.5[\mathrm{~W} / \mathrm{kg}]$ and then decreases to $0[\mathrm{~W} / \mathrm{kg}]$. After that, power fluctuates because of the swing motion of leg. 

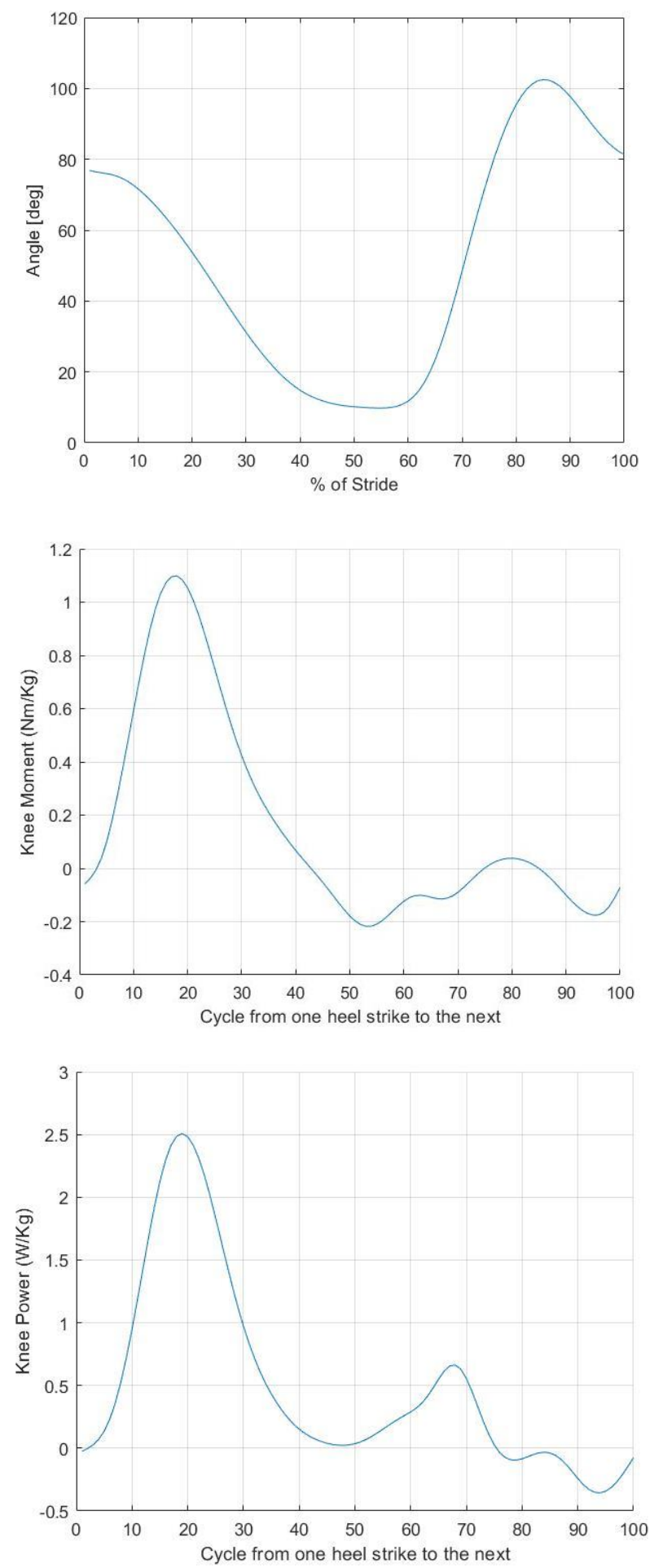

Figure 4. Angle (top), moment (middle) and power (bottom) plots of knee joint during stair ascent (Riener et.al., 2002)

\section{Design}

\subsection{Weight Acceptance Spring}

In human gait, knee joint produces the highest torque during weight acceptance in the stance phase. According to bio-mechanical data, torque increases and decreases approximately in a linear fashion. This shows that an elastic element can be used to mimic the knee joint during this part of the gait as shown in Figure 5. 


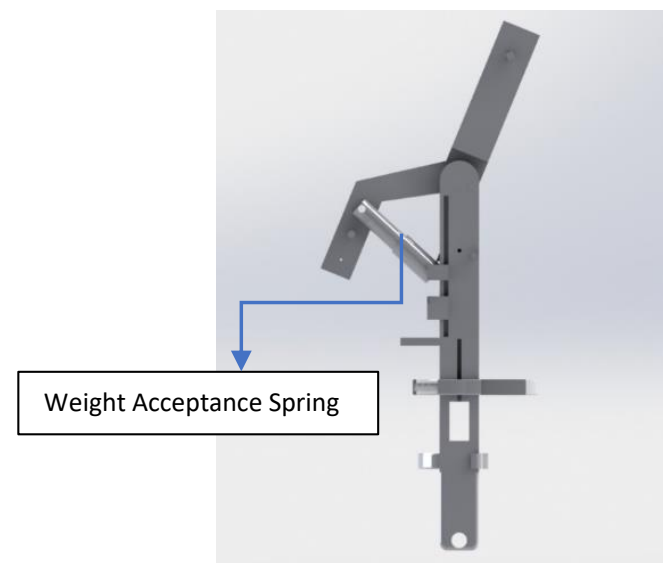

Figure 5. Weight acceptance spring

It is crucial to determine the spring coefficient in order to assist the weight acceptance properly and safely. To do this, we approximate the linear spring force data from translating the required knee joint torque to force data and with the related elongation data we could obtain the coefficient of elastic element as shown in Figure 6. Here, initially we decided to place the spring $80 \mathrm{~mm}$ away from the knee joint for both attachment points to avoid large design (see Figure 5). in the Two characteristic behaviors can be seen in this figure. The behavior with high slope represents the weight acceptance, and the other one represents the push-off and swing phase of gait. In order to determine the spring coefficient, the slope of the red line has been computed.

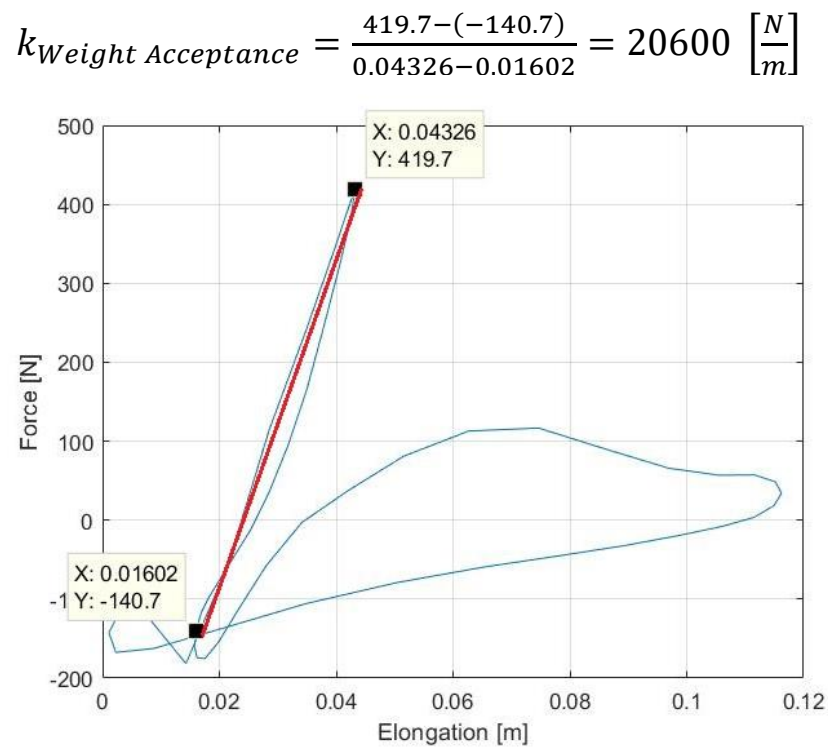

Figure 6. Force-elongation plot of WA spring

\subsection{Sit-to-Stand Spring}

As we already mentioned in previous section, this task can be approximated by a linear spring. To be able to find the coefficient of that spring, we generate the force data that is needed to produce the knee torque vs. elongation of elastic element plot in Figure 7. Here, initially we decided to place the spring $100 \mathrm{~mm}$ away from the knee joint for both attachment points to avoid large design (see Figure 2). The slope of the red line defines the spring coefficient which is:

$$
k_{\text {Sit to Stance }}=\frac{2152-489.6}{0.1488-0.04103}=15425[\mathrm{~N} / \mathrm{m}]
$$




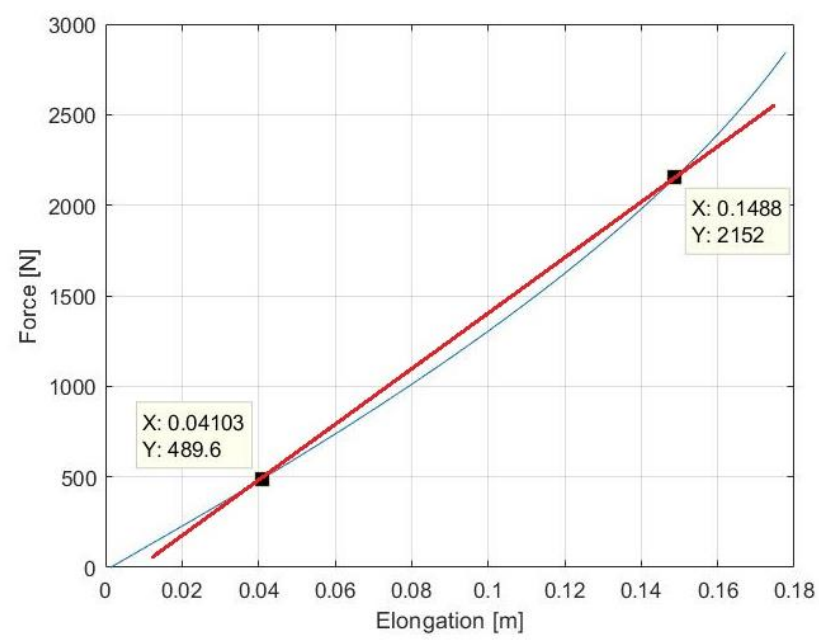

Figure 7. Force-elongation plot of sit to stand spring

\subsection{Stair Ascend Mechanism}

For assisting stair ascend we used actuator including a dc motor with spring mechanism to mimic the knee joint. After analyzing the ascent data, the spring that is employed on the actuator to reduce the motor size for generating the motion of stair ascent motions is determined.

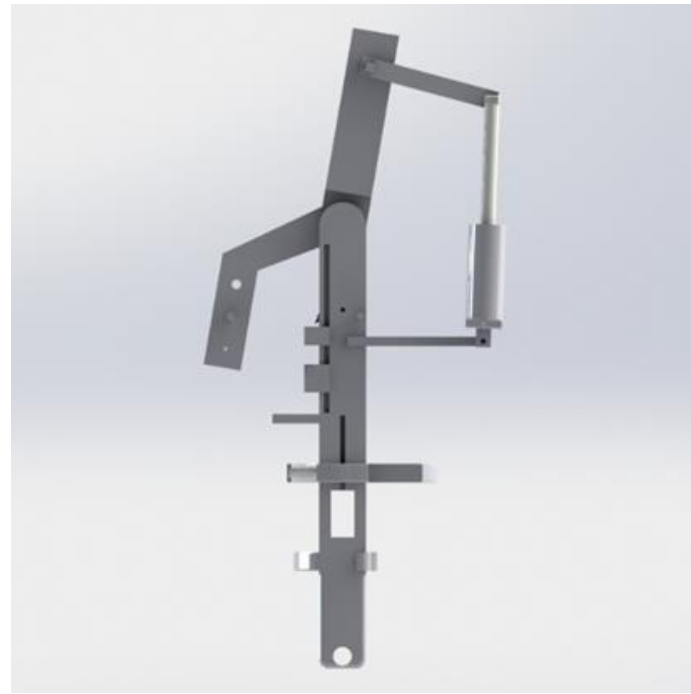

Figure 8. Stair ascent actuator

Specifically, in order to determine that spring, force vs. elongation plot of the elastic element during stair ascent motion is generated and examined. Figure 9 depicts the force vs. elongation plot of the spring during stair ascent. Here, initially we decided to place the actuator $100 \mathrm{~mm}$ away from the knee joint for both attachment points to avoid large design (see Figure 8). 


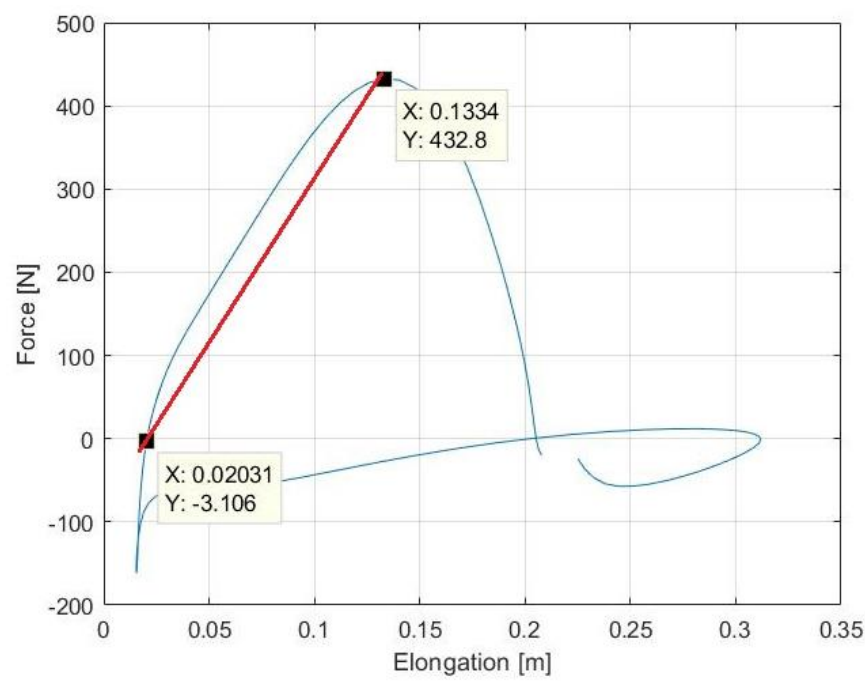

Figure 9. Force vs. elongation plot of spring during stair ascent

There are two phases in this figure. The phase with higher slope represents the max. torque generation by knee during ascent. The second phase with lower slope stands for the swing motion of the leg. So, the slope of the red line in Figure 9 can be used as coefficient of the spring.

$$
k_{\text {Ascent }}=\frac{432.8-(-3.106)}{(0.1334-0.02031)}=3854[\mathrm{~N} / \mathrm{m}]
$$

\section{Result and Discussion}

When simulating the exoskeleton with the WA spring during walking, the system can mimic the knee joint as it is shown in Figure 10, which makes the comparison of knee joint and knee exoskeleton torque during WA.

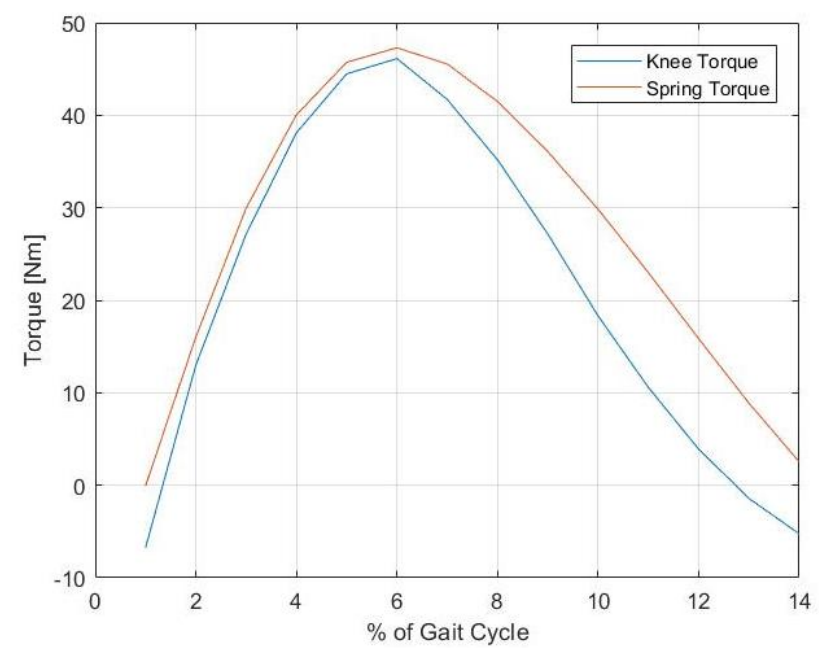

Figure 10. Comparison of natural knee joint and exoskeleton torque during WA

Similar behavior is also observed when simulating the exoskeleton during sit to stand motion, which is shown in Figure 11 as a comparison of knee joint and knee exoskeleton torque during sit to stand motion. The reason for the difference between the knee joint and the exoskeleton torque would be due to linearization of the forceelongation curve for the sit to stand motion. 


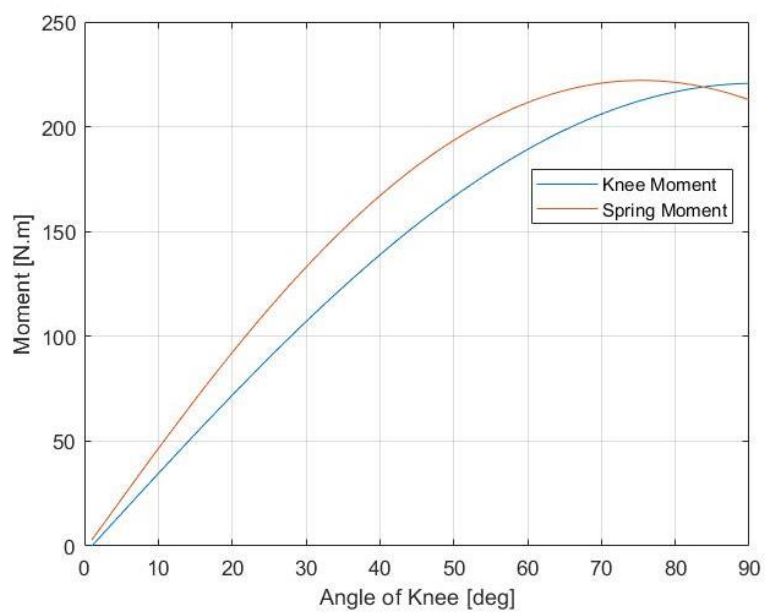

Figure 11. Comparison of the knee joint and exoskeleton torque during sit to stand

The comparison of knee joint and exoskeleton torque and power plots during stair ascent motion is depicted in Figure 12. Here, the moment of natural knee joint starts from $0 \mathrm{Nm}$, yet the initial moment of exoskeleton is nearly $180 \mathrm{Nm}$. It means that the actuator has to compress to spring because of the kinematic restrictions. Then it releases the spring and after $20 \%$ motor does not have to apply power. So the spring is supportive to raise the body, which can be seen as the power reduction in Figure 12. Actuator consumes power until 20\% then required power decreases to nearly zero, since spring does the job after $20 \%$ of the cycle. After $40 \%$ of cycle, spring restricts the swing motion due to the kinematics of our design. To be able to avoid this, the design includes an engage-disengage mechanism to engage the spring only between $0-40 \%$ and disengage the spring $40-100 \%$ so that the actuator does not consume unnecessary power. Because of the spring only works between 0-40\% of gait cycle, we plotted only this part.
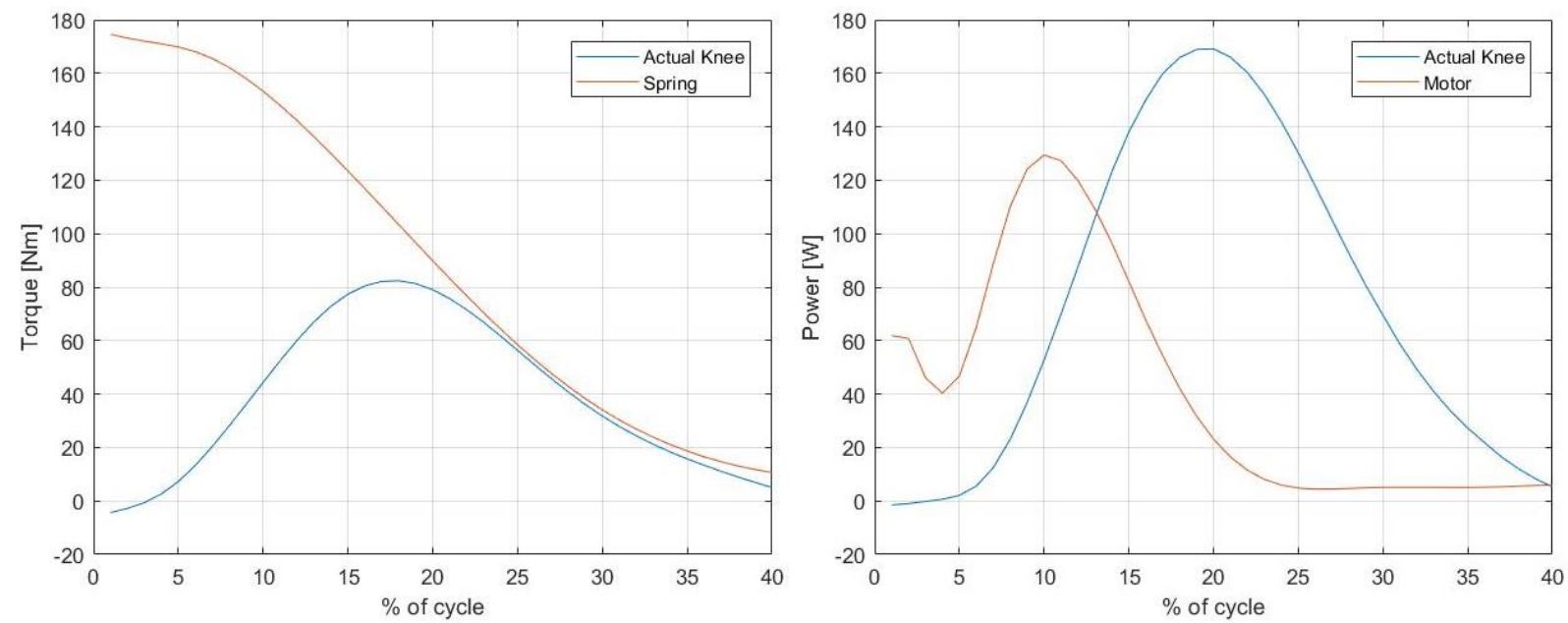

Figure 12. Comparison of Moment (left) and Power (right) plots of knee during ascending

The complete CAD of the proposed exoskeleton design is presented in Figure 13 as it is attached to human leg. 


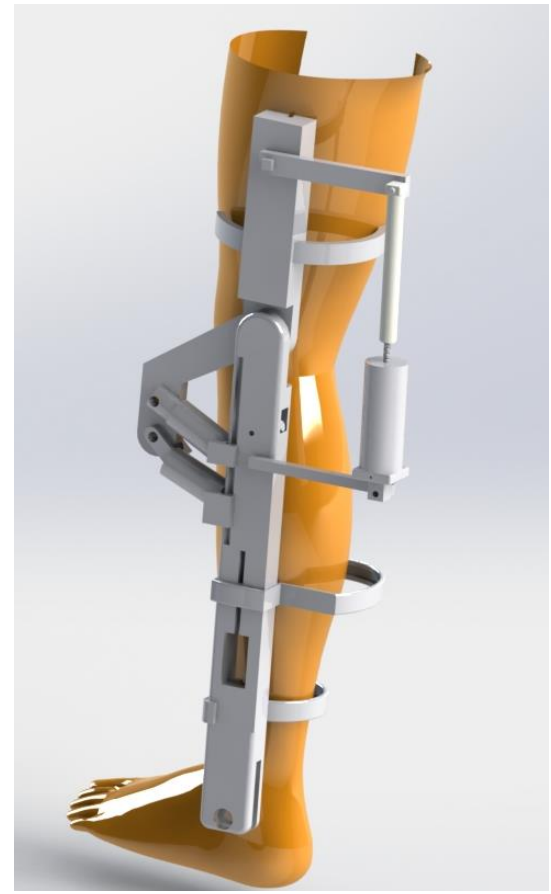

Figure 13. 3D CAD model of exoskeleton design

\section{Conclusion and Futurework}

In this paper we presented a conceptual design of a knee exoskeleton that assists weight acceptance, sit to stand and stair ascent motions. To be able to do this, first, the biomechanical data of these motions were analyzed. Then, considering these data, coefficients of springs that would aid these motions were determined. Results showed that even though there are some differences between the actual data and our design, using elastic elements would be sufficient to assist these motions to achieve energy-efficient devices. Differences are mainly due to non-linear elastic behavior of the natural knee joint, in other words, variable joint stiffness during these motions. However, we apply these motions with linear springs on the exoskeleton, so the exoskeleton joint have constant elastic coefficient. For stair ascent motion, we used an actuator that combines spring and a dc motor with a ball-screw mechanism. Motor is employed to compress the spring, then, together with the spring this actuator assists to raise the body. With this combination the maximum power consumption decreased from nearly $170 \mathrm{~W}$ to $130 \mathrm{~W}$ in comparison to direct-drive of the knee joint with a dc motor. Currently we are building the prototype of this conceptual design to test the device first functionally and then on individuals to evaluate the performance of the device.

\section{Acknowledgement}

This research study has been supported by Abdullah Gül Üniversitesi Bilimsel Araștırma Projeleri Koordinasyon Birimi under the project number FAB-2017-89. Authors would like to thank Prof. Dr. Robert Riener for sharing the biomechanical data of stair-climbing.

\section{Conflict of Interest}

No conflict of interest was declared by the authors.

\section{References}

Againer-ski, 2017. Againer-ski | Maximize your skiing. [Online]. Available: http://againer-ski.com/?v=ebe021079e5a.

Agrawal, S.K., Banala, S.K., Fattah, A., 2006. A gravity balancing passive exoskeleton for the human leg. Proceedings of Robotics: Science and Systems.

Bacek, T., Unal, R., Moltedo, M., Junius, K., Cuypers, H., Vanderborght, B., Lefeber, D., 2015. Conceptual design of a novel variable stiffness actuator for use in lower limb exoskeletons. IEEE International Conference on Rehabilitation Robotics (ICORR), Singapore, 583-588.

Banala, S.K., Agrawal, S.K., Scholz, J.P., 2007. Active Leg Exoskeleton (ALEX) for Gait Rehabilitation of Motor-Impaired Patients. IEEE International Conference on Rehabilitation Robotics (ICORR), 401-407. 
Baser, O., Sekerci, B., Kizilhan, H., Kilic, E., 2018. İnsan ve Alt Uzuv Dış İskelet Robotun Matlab Simmechanıcs Ortamında Modellenmesi ve Etkileșim Kuvvetlerinin Minimize Edilmesi Kontrol Çalıșması. Mühendislik Bilimleri ve Tasarım Dergisi, $6(3), 365-374$.

Baser, O., Kizilhan, H., Kilic, E., 2019. Biomimetic compliant lower limb exoskeleton (BioComEx) and its experimental evaluation. Journal of the Brazilian Society of Mechanical Sciences and Engineering, 41(5), 226

Baser, O., Kizilhan, H., Kilic, E., 2020. Employing variable impedance stiffness damping hybrid actuators on lower limb exoskeleton robots for stable and safe walking trajectory tracking. Journal of Mechanical Science and Technology, 34(6), 2597-2607.

Beyl, P., Naudet, J., van Ham, R., Lefeber, D., 2007. Mechanical design of an active knee orthosis for gait rehabilitation. IEEE 10th International Conference on Rehabilitation Robotics (ICORR), 100-105.

Cai, V.A., Bidaud, P., Hayward, V., Gosselin, F., Desailly, E., 2011. Self-adjusting, isostatic exoskeleton for the human knee joint. Conference Proceedings IEEE Engineering in Medicine and Biology Society, 612-618.

Celebi, B., Yalcin, M., Patoglu, V., 2013. AssistOn-Knee: A self-aligning knee exoskeleton. IEEE/RSJ International Conference on Intelligent Robots and Systems, 996-1002.

Cheng, H.S., Ju, M.S., Lin, C.C.K., 2003. Improving Elbow Torque Output of Stroke Patients with Assistive Torque Controlled by EMG Signals. Journal of Biomechanical Engineering, 125(6), 881.

Cheng P-T, Wu S-H, Liaw M-Y, Wong AMK, Tang F-T, 2001. Symmetrical body-weight distribution training in stroke patients and its effect on fall prevention. 82(12), 1650-1654.

Demiray, M.A., Baser, O., Kilic, E., 2014. Alt Uzuv Dış İskelet Robot Eklemlerinde Kararlılık İçin Sönümleme Katsayıları ve Momentlerinin Hesaplanması. Süleyman Demirel Üniversitesi Fen Bilimleri Enstitüsü Dergisi, 18 (3), 34-51.

Dollar, A.M., Herr, H., 2008. Design of a quasi-passive knee exoskeleton to assist running. IEEE/RSJ International Conference on Intelligent Robots and Systems, IROS, 747-754.

Erdogan, A., Celebi, B., Satici A.C., Patoglu, V., 2016. AssistOn-Ankle: A Reconfigurable Ankle Exoskeleton with Series-Elastic Actuation. Autonomous Robots, 41, 1-16.

Hu, X.L., Tong, K.Y., 2009. Interactive Rehabilitation Robot for Hand Function Training. IEEE International Conference on Rehabilitation Robotics (ICORR), 777-780.

Highsmith, M. J., Kahle, J. T., Carey, S. L., Lura, D. J., Dubey, R. V., Csavina, K. R., and Quillen, W. S., 2011. Kinetic Asymmetry in Transfemoral Amputees While Performing Sit to Stand and Stand to Sit Movements. Gait and Posture, 34(1), 86-91.

Indego, 2017. Indego - Powering People Forward [Online]. Available: http://www.indego.com/indego/en/home.

Jezernik, S., Colombo, G., Keller, T., Frueh, H., Morari, M., 2003. Robotic Orthosis Lokomat: A Rehabilitation and Research Tool. Neuromodulation, 6(2), 108-115.

Kazerooni, H., Steger, R., Huang, L., 2006. Hybrid Control of the Berkeley Lower Extremity Exoskeleton (BLEEX). International Journal of Robotics Research, 25(5-6), 561-573.

Karavas, N., Ajoudani, A., Tsagarakis, N., Saglia, J., Bicchi, A., Caldwell, D., 2015. Tele-impedance based assistive control for a compliant knee exoskeleton. Robotics and Autonomous Systems, 73, 78-90.

Kiguchi, K., Iwami, K., Yasuda, M., Watanabe, K., Fukuda, T., 2003. An exoskeletal robot for human shoulder joint motion assist. IEEE/ASME Transactions on Mechatronics, 8(1), 125-135.

Kim, J.-H., Shim, M., Ahn, D. H., Son, B. J., Kim, S.-Y., Kim, D. Y., ... Cho, B.-K., 2015. Design of a Knee Exoskeleton Using Foot Pressure and Knee Torque Sensors. International Journal of Advanced Robotic Systems.

Kizilhan, H., Baser, O., Kilic, E., Ulusoy, N., 2014. Dış İskelet Robot Eklemleri için Antagonistik ve Öngerilmeli Tip Sertliği Değiştirilebilir Eyleyici Tasarımlarında Güç Gereksinimi ve Enerji Sarfiyatı Karşılaştırması. Süleyman Demirel Üniversitesi Fen Bilimleri Enstitüsü Dergisi, 18(3), 77-91.

Lee, M., Wong, M., Tang, F., Cheng, P., Lin, P., 1997. Comparison of Balance Responses and Motor Patterns During Sit-To-Stand Task with Functional Mobility in Stroke Patients. American Journal of Physical Medicine \& Rehabilitation, 76(5), 401-410.

Liu, X., Low, K.H., 2004. Development and preliminary study of the NTU lower extremity exoskeleton. IEEE Conference on Cybernetics and Intelligent Systems, 2, 1243-1247.

Lockheed Martin, 2017. Exoskeleton Technologies: Industrial. [Online] Available: https://www.lockheedmartin.com/us/products/exoskeleton/industrial.html.

Paine, N., Oh, S., Sentis, L., 2014. Design and control considerations for high-performance series elastic actuators. IEEE/ASME Transactions on Mechatronics, 19(3), 1080-1091.

Plagenhoef, S., Evans, F.G., Abdelnour, T., 1983. Anatomical Data for Analyzing Human Motion. Research Quarterly for Exercise and Sport, 54(2), 169-178.

Pratt, J.E., Krupp, B.T., Morse, C.J., Collins, S.H., 2004. The RoboKnee: an exoskeleton for enhancing strength and endurance during walking. IEEE International Conference on Robotics Automation (ICRA), 2430-2435.

ReWalk, 2017. ReWalk 6.0 - Home. [Online]. Available: http://rewalk.com/.

Rex, 2017. Rex Bionics - Step into the future. [Online]. Available: https://www.rexbionics.com/.

Riener, R., Rabuffetti, M., Frigo, C., 2002. Stair ascent and descent at different inclinations. Gait \& Posture, 15(1), 32-44.

Sasaki, D., Noritsugu, T., Takaiwa, M., 2005. Development of active support splint driven by pneumatic soft actuator (ASSIST). IEEE International Conference on Robotics \& Automation (ICRA), 520-525.

Shamaei, K., Cenciarini, M., Adams, A.A., Gregorczyk, K.N., Schiffman, J.M., Dollar, A.M., 2014. Design and evaluation of a quasipassive knee exoskeleton for investigation of motor adaptation in lower extremity joints. IEEE Transactions on Biomedical Engineering, 61(6), 1809-1821.

Shepherd M.K., Rouse, E.J., 2017. Design and Validation of a Torque-Controllable Knee Exoskeleton for Sit-to-Stand Assistance. IEEE/ASME Transactions on Mechatronics, 22(4), 1695-1704.

Sulzer, J.S., Roiz, R.A., Peshkin, M.A., Patton, J.L., 2009. A Highly Backdrivable, Lightweight Knee Actuator for Investigating Gait in Stroke. IEEE Transactions on Robotics, 25(3), 539-548.

van Dijk, W., van der Kooij, H., 2014. XPED2: A Passive Exoskeleton with Artificial Tendons. IEEE Robotics \& Automation Magazine, 21(4), 56-61. 
van der Kooij, H., Veneman, J., Ekkelenkamp, R., 2006. Design of a compliantly actuated exo-skeleton for an impedancecontrolled gait trainer robot. IEEE Engineering in Medicine and Biology Society (EMBS), 189-193.

Wang, D., Lee, K.M., Ji, J., 2016. A Passive Gait-Based Weight-Support Lower Extremity Exoskeleton with Compliant Joints. IEEE Transactions on Robotics, 32(4), 933-942.

Wilken, J. M., Sinitski, E.H., and Bagg, E.A., 2011. The Role of Lower Extremity Joint Powers in Successful Stair Ambulation. Gait and Posture, 34(1), 142-144.

Winter, D.A., 1991. The Biomechanics and Motor Control of Human Gait. University of Waterloo Press.

Wong, C.K., Bishop, L., Stein, J., 2012. A wearable robotic knee orthosis for gait training. Prosthetics and Orthotics International, 36(1), 113-120.

Wretenberg, P., Arborelius, U.P., 1994. Power and work produced in different leg muscle groups when rising from a chair. European Journal of Applied Physiology, 68, 413-417.

Wu, J., Gao, J., Song, R., Li, R., Li, Y., 2016. The design and control of a 3DOF lower limb rehabilitation robot. Mechatronics, 33, $13-22$.

Zissimopoulos, A., Fatone, S., and Gard, S. A., 2007. Biomechanical and Energetic Effects of a Stance-Control Orthotic Knee Joint. Journal of Rehabilitation Research and Development, 44(4), 503. 